\title{
Biomedical engineering in Nigeria: The genesis, present and the future
}

\author{
Bamigboye, A. A. ${ }^{*}$ and Bello, K. A. ${ }^{2}$ \\ ${ }^{1}$ Department of Obstetrics and Gynecology, Faculty of Clinical Sciences, AfeBabalola University Ado-Ekiti (ABUAD), \\ P. M. B. 5454, Nigeria. \\ ${ }^{2}$ Department of Mechanical and Mechatronics Engineering, AfeBabalola University Ado-Ekiti (ABUAD), P. M. B. 5454, \\ Nigeria.
}

Received 11 June, 2019: Accepted 24 March, 2020

\begin{abstract}
Inadequate biomedical engineering (BME) training, the gross deficit in the maintenance of biomedical facilities, mismanagement of resources allocated to the hospital biomedical unit by the management coupled with poor maintenance culture, are some of the factors that can aggravate the already high mortality rate, short life expectancy, poor economic growth, and low quality of life index in Africa, South of Sahara, and in Nigeria in particular. This synopsis serves to review the practice of biomedical engineering in Nigeria and also identify relevant factors that palpably influence BME development in Nigeria. Wide gamut of literature survey was carried out with the view to trace the activities of BME from the origin of BME in Nigeria till date. The result shows that the slow rate of BME development in Nigeria could be traced to relatively low allocation in the National budget on health, mismanagement, ignorance of recent advanced technology with poor or lack of personnel and is found to affect technological development of biomedical engineering. This study would serve as a guide to Nigerian government and other relevant stakeholders as a matter of urgency to declare a state of emergency in the health sector and particularly in the field of BME by collaborating with international professional bodies.
\end{abstract}

Key words: Biomedical engineering, biomedical development, healthcare operations, low budget allocation, medical treatment.

\section{INTRODUCTION}

The measure of the quality of health attainable by a nation is proportional to the level of BME practice in such a nation. No nation enjoys medical facilities above its level of BME development. Therefore, the biomedical engineering practices play a significant role in promoting quality of health delivery. Biomedical engineers combine the knowledge of the physical structure and functions of the human body systems with the concepts of engineering principles and applications to solve medical and medicalrelated problems (http:bines.seas.wustl.edu/WhitakerArchives/glances/defi nition.html). Biomedical engineering can be expressed as the application of engineering principles and technical innovation techniques to solve medical problems. BME consists of research and development; it includes the studies of the human body from the perspective of

*Corresponding author. E-mail:aabamig@gmail.com

Author(s) agree that this article remain permanently open access under the terms of the Creative Commons Attribution License 4.0 International License 
engineering concepts to develop devices that enhance medicine and healthcare. BME significant medical field in Nigeria includes biomaterials, biomechanics, cardiovascular and biofluid mechanics, bio instrumentation, the physical and mechanical behavior of tissues treated on engineering materials, the body response to implant materials, and bioengineering analysis of physiological control of heart, respiration, artificial human organs development, implantable devices and finite element models (Okorie, 2015). Biomedical engineering originated centuries ago (Nkuma-Udah and Mazi, 2009) in its rudimentary levels. metamorphosized to a global professional in 1959 and was embraced in Nigeria as organized engineering practice in the 1970s. Although BME is not entirely a new profession in Nigeria, it is yet to achieve a significant role in Nigeria lowresourced health care facilities practice. This is due to poor capacity building, limited financial resources for procurement/maintenance of equipment and poor modern healthcare technologies. The Nigerian Institute of biomedical engineering (NIBE) was established two decades ago with a mandate of promoting biomedical engineering profession. It collaborates with IFMBE. The growth of the association has been stunted in a clime where no single functioning manufacturing company exists despite a population of about 200 million Nigerians. However, few BME research practices occur in academic and health institutions. Only clinical engineering appears to be active as against bio-instrumentation, biomaterials, Orthopedic bioengineering, Rehabilitation engineering, system physiology just to mention few.

The activities of BME in Nigeria started in the 1970s. Although, the pace of development was slow and limited to professional development and workers welfare instead of embracing the totality of BME fields which include: biomaterials, biomechanics, cardiovascular and biofluid mechanics, bio-instrumentation, research, and development. Again, the inauguration of NIBE in 1999 witnessed constant progress in BME activities.

\section{METHODOLOGY}

The exploratory survey on the state of BME in Nigeria was conducted by reviewing the wide literature in BME in Nigeria's Teaching hospitals, Research institutions, Professional bodies, World Health Organization reports, etc.

\section{HISTORY OF BME IN NIGERIA}

BME department was first established in the University of Lagos, Nigeria over four decades ago to conduct training for low and middle-level human resources in BME (Nkuma-Udah et al., 2015). BME first conference was held in 1974 under the umbrella of Nigerian Association of Health Engineering which was later inaugurated as NIBE three decades ago with the vision to initiate and propagate biomedical technology in relation to health in the country. NIBE contribution to BME development are numerous and these include organizing the first biomedical engineering annual conference in 2000; monthly publication of BME journals since 2001; enrollment in IFMBE in 2003 as the $50^{\text {th }}$ member and establishment of National Postgraduate College of Biomedical Engineering of Nigeria (NPCBN) in 2009 to promote biomedical training in Nigeria. Other NIBE contributions include establishment of BME profession in Africa to supervise and implement to commence biomedical engineering development in Africa. Even though the BME profession in Nigeria is not entirely new, there is still no single BME Research Centre and manufacturing firm that producebiomedical equipment in Nigeria.

\section{BME DEVELOPMENT IN NIGERIA}

Biomedical engineering profession has witnessed major progress in Nigeria in the area of personnel training since the inauguration of NIBE in 1999. This achievement could be traced to BME training practices such as short courses and continuing professional development, along with the establishment of Biomedical Engineering Postgraduate College in Nigeria. Again, the National University Commission (NUC) approved few notable universities in Nigeria for the purpose of manpower training, and BME Development and Biomedical Technology degree programs. The Universities approved include Afe Babalola University, Ado Ekiti, University of Ilorin, Federal University of Technology, Owerri, Bells University Ota, University of Port Harcourt, and Delta State University, Asaba. The purpose of degree programs in BME is for middle and top-level manpower development in BME \& $T$ to sustain BME practice at all level. BME practice in Nigeria is divided into the following professional aspects: the research and development, industry, clinical and health academia. In Nigeria, the biomedical engineering impact is mostly felt in the clinical section. Till date, no center for research is solely dedicated to BME in Nigeria, this is a great challenge. However, few medical engineering researches are being conducted in some research institutes in the ministries of health, science, and technology. In academia, a lot of educational, research and training efforts have been undertaken for the purpose of biomedical engineering development in Nigeria. However, no biomedical equipment manufacturing company existsin Nigeria till the moment.

\section{NIGERIA BME CHALLENGES}

Biomedical development in Nigeria is facing a lot of obstacles varying from financial resources, limited access 
to healthcare technologies, poor access to professional information, low budget allocation to health and education sectors, and many more. These pose more challenges to BME professional development in Nigeria. Again, no available research laboratories and libraries to promote BME training to an internationally competitive standard, no indigenous center in Nigeria for Biomedical instrumentation and equipment design, development, evaluation, and maintenance to facilitate BME practice. In addition, data management and preservation of medical records are absent, and no Biomedical engineering clinical internship programs for BME students to balance theoretical and practical knowledge. BME in Nigeria is underdeveloped in the area of education, training, and practice. For instance, the World Health Organization (World Health Organization, 2017; Nkuma-Udah, 2008) noted, half of the medical facilities in developing countries (Nigeria inclusive) is malfunctioning, misused, and not properly maintained. Besides, there is a shortfall in trained biomedical personnel, absence of BME technicalknow-how, and no healthcare management (HTM) in Nigeria. Many Africa countries including Nigeria, depends on the medical donation, even at that, the challenges of installation, manpower training and maintenance is grossly inadequate (Schneiber et al., 2010). In addition, most of the donated medical equipment are refurbished and obsolete. Therefore, modern and advanced medical technologies are not accessible in most Nigerian hospitals even after several years of their existence because of the financial impediment. Till date, Federal government annual budget in Nigeria, which is about $3.5 \%$ on health, is far below WHO recommendation. The aforementioned challenges are part of the reasons why government officials and the rich in Nigeria are traveling to developed nations to access quality medical treatment (Gehlot, 2009; Webster, 2006).

\section{THE NEEDS FOR FUNCTIONING BME IN NIGERIA}

The applications of engineering and technological knowhow to health care systems assure high-quality service delivery, effective diagnosis, affordable charges, and functional modern equipment (Brozino, 2000) required by pursuing the following:

a) To promote health and well-being of patients by using technological awareness the approach in diagnosing, treating, rehabilitating and preventing ailments at all levels of healthcare services.

b) Innovating, developing, designing, installing, managing, evaluating, comparing and maintaining $\mathrm{BME}$ equipment for safe and cost-effective application.

c) Engaging engineering design and considerations to medicine for the purpose of discovering better ways to solve health issues. d) Designing quality devices, control processes, unique techniques and software applications in healthcare treatment such as consumables, artificial organs, and prosthesis to promote and support life.

e) Daily living support reinstatement such as prosthesis leg, wheelchairs, hearing aid and personal emergency response equipment.

f) Designing and development of functional engineering devices to sustain healthcare operations in disaster management.

g) Designing and development of technical devices for supporting vital sensitive areas such as reproductive, child health and cardiac.

h) Designing, developing and using safety technicality to eliminate risks associated with medical tools handling.

\section{CONCLUSIONS}

The Biomedical engineering transition in Nigeria from the griddle has witnessed various developmental stages from a very humble beginning to the present stage. Although there are many issues that predicate against the BME growth in Nigeria, these include inadequate financial resources, limited sources to healthcare technologies, poor access to professional information, low budget allocation to health and education sectors among others. A deliberate effort has been geared towards promoting BME in Nigeria since the advent of NIBE in 1999. The NIBE affiliation with IFMBE has given way to collaboration and opportunity to develop BME training and academic research in few Nigeria Universities. Thus, the subject of discussion on challenges of BME profession and practice is serving as the basis for creating awareness and balance of thought among the stakeholders. NIBE should continue to champion the need for government and private sector participation in the BME manpower development, research development, equipment design and manufacturing, maintenance and service of equipment, and many more until the BME practice in Nigeria is comparable to what is attainable in the developed nations.

\section{RECOMMENDATIONS}

1) Declaration of state of emergency in the health sector and BME field by the government will serve as a remedy to health challenges in Nigeria.

2) Blueprint on BME strong values is needed.

3) Collaboration between international professional bodies and Nigerian universities that are currently running BME and BME related courses will alleviate the problem of manpower in various BME fields. It will enhance access to good quality health medical diagnosis and treatment in Africa and Nigeria in particular. 


\section{CONFLICT OF INTERESTS}

The authors have not declared any conflict of interests.

\section{REFERENCES}

Brozino JD (2000). The biomedical engineering Handbook. Second edition. ISBN-13: 978-0849385940.

Definition of Biomedical Engineering, Whitaker foundation http:bines.seas.wustl.edu/Whitaker Archives/glances/definition.html

Gehlot NS (2009). Recent development in biomedical engineering education and research. Conference proceeding IEEE Med Boil Scopp, pp.5862:5865

Nkuma-Udah KI, Mazi EA (2009). Biomedical Engineering in Nigeria: An impetus for an Enduring African. Biomedical Engineering African Journal of Medical Physics, Biomedical Engineering and Sciences 1:5-10.

Nkuma-Udah K I, Agoha EEC, Ejeta K, Ndubuka GI (2015). Biomedical Engineering in Nigeria: A Developmental Overview. If, MBE preceding. Vol.51 DOI: 10.1007/987-3-319-19387-8-400.

Nkuma-Udah KI (2008). Ethics and Professional Practice of Biomedical Engineering in Nigeria: Regulations and organization.
Okorie PU (2015).The significant of Biomedical Engineering to medical field in Nigeria. America Journal of Biomedical Science and Engineering 1(2):20-24.

SchneiberB, Schneicher FK, Dallabona CA (2010).The role of biomedical engineering in health systems improvement and nation development. Conference proceeding IEEE Med Boil Scopp.62486251.

The World Health Organization (2017). Human resources for medical devices the role of Biomedical Engineer. WHO medical devices technical series.

Webster JG (2006). The ten most important biomedical engineering devices. World congress on medical physics and biomedical engineering proceeding (14/2): 664-665 